OPEN ACCESS

Edited by:

Mengcheng Wang,

Guangzhou University, China

Reviewed by:

Jinbo He,

The Chinese University of Hong Kong,

Shenzhen, China

Candido J. Ingles,

Universidad Miguel Hernández

de Elche, Spain

*Correspondence:

Zheng Luo

luozheng@cnu.edu.cn

Specialty section:

This article was submitted to

Quantitative Psychology

and Measurement,

a section of the journal

Frontiers in Psychology

Received: 29 May 2019

Accepted: 26 September 2019

Published: 11 October 2019

Citation:

Luo Z, Dang Y and Xu W (2019)

Academic Interest Scale

for Adolescents: Development,

Validation, and Measurement

Invariance With Chinese Students.

Front. Psychol. 10:2301.

doi: 10.3389/fpsyg.2019.02301

\section{Academic Interest Scale for Adolescents: Development, Validation, and Measurement Invariance With Chinese Students}

\author{
Zheng Luo*, Yun Dang and Wenjie Xu \\ Beijing Key Laboratory of Learning and Cognition, School of Psychology, Capital Normal University, Beijing, China
}

Hidi and Renninger's four-phase interest development model was identified as the most complete and widely used theoretical model illustrating the essence of academic interest. Using the model along with current research literature as a basis, this study aimed to develop and initially validate a generic multidimensional instrument to measure academic interest across different school subjects in the Chinese education context; this instrument was called the Academic Interest Scale for Adolescents (AISA). Three large samples of Chinese junior high school students were recruited by cluster sampling in the study. (1) Sample 1 ( $N=552 ; 45.5 \%$ girls; 12.31 [SD = 0.98] years, range $=10-15$ years) completed the draft of AISA, Intrinsic Motivation Scale and Scale for Adolescents' Flow State in Learning in math and English. (2) Sample 2 (a subgroup of Sample 1, 411 students) completed the AISA in math and English again 2 months later after the first survey. (3) Sample 3 ( $N=1,780 ; 50.1 \%$ girls; 13.69 [SD $=0.97$ ] years, range $=12-$ 16 years) completed the AISA in math, English, and Chinese. Identically worded items were used in AISA, except for the name of the subject. An exploratory factor analysis for math in sample 1 using principle axis factoring and promax rotation resulted in a 29item AISA containing four dimensions: emotion, value, knowledge, and engagement, and the latent variables together explained $59.40 \%$ of the total variance. Confirmatory factor analysis for math, English, and Chinese in sample 3 suggested the four-factor model fits well in different samples and subjects. Scale scores showed adequate internal consistency (the Cronbach's $\alpha$ for AISA and each subscale ranged from 0.86 to 0.93) and acceptable test-criterion relationships (correlations between the AISA score and intrinsic motivation and flow state in learning $>0.51$, ps $<0.001$ ). Furthermore, the structural measure invariance across subjects, time (2-month interval), genders and grades were upheld. The AISA promises to be a useful tool for the evaluation of academic interest among Chinese adolescents and can be administered in different educational settings, i.e., different subjects, time, genders, and grades.

Keywords: Academic Interest Scale for Adolescents (AISA), academic interest, four-phase interest development model, scale development, measure invariance 


\section{INTRODUCTION}

Since Herbart (1776-1841) began to consider fostering interest as one of the primary goals of education, researchers have investigated the contribution of student interest to academic achievement. It has been widely acknowledged that interest promotes engagement, efficiency, effort, and persistence in learning (e.g., Dewey, 1913; Mitchell, 1993; Lipstein and Renninger, 2006; Trautwein et al., 2015). Unfortunately, studies have indicated that interest in most school subjects shows a downward trend over time (Hidi and Harackiewicz, 2000; Krapp, 2002; Dotterer et al., 2009; Frenzel et al., 2010). This trend not only occurs in primary school but also seems to be more obvious in middle school (Prenzel, 1998). In China, the lack of academic interest is common among primary and middle school students. There is even a term for it known as learning weariness. A Study found that $17.38 \%$ junior high school students in rural areas of China reported to have suffered from learning weariness (Zhao, 2015). Theoretical as well as empirical research emphasized that students' individual factors (e.g., Schurtz et al., 2014; Zhang et al., 2018; Denner et al., 2019) along with environmental factors (e.g., Lazarides et al., 2019) are all important predictors of their academic interests. As for learning weariness of Chinese students, one of the main reasons is the heavy academic burden (Guo and Zhang, 2012).

A number of self-report instruments have been developed to assess the level of academic interest and associations with academic performance among adolescents in Western countries (e.g., Dotterer et al., 2009; Kalender and Berberoglu, 2009; Linnenbrink-Garcia et al., 2010; Rotgans, 2015). Most of these scales were limited to measurement of emotion or value components in academic interest. Meanwhile, the measurement invariance of the instrument across subjects, time, genders, and grades has not been fully tested. In China, most early academic interest measures adopted single item or single dimension, which have not yet been fully validated ( $\mathrm{Tu}$ and $\mathrm{He}, 2013$ ). The current measures focus on subject-specific interest, such as mathematics learning interest questionnaire (MLIQ, Wu and Liu, 2017) for junior high school students and sports learning interest scale (SLIS, Lin and Chai, 2017) for primary and secondary school students. Therefore, to study the multifactorial nature and academic effects of academic interest and provide effective prevention and intervention ideas for loss of interest, it is necessary to develop a more comprehensive tool for assessing Chinese adolescents' academic interest across different educational contexts.

\section{Definition of Academic Interest}

Interest, which is a unique motivational variable, refers to a preferred engagement of a person with a specific object (i.e., a certain topic, activity, and idea), which can display itself as a psychological state as well as the relatively enduring predisposition toward these objects (Hidi and Renninger, 2006). According to the person-object theory of interest (POI; Krapp, 2000, 2005), the development of interest relies on the ongoing interactions between the environment (object) and the person. Furthermore, interest can be divided into situational interest and individual interest (e.g., Hidi, 1990; Krapp et al., 1992; Krapp, 2000, 2005). Situational interest is a state of focused attention and affective reaction elicited by current environmental stimuli (Hidi and Baird, 1986; Hidi, 1990), Whereas individual interest is a sustained preference for particular content (Krapp and Fink, 1992; Renninger, 2000). Individual interest develops from situational interest (Hidi and Renninger, 2006). Both types of interest have been shown to positively influence attention, cognitive performance, and affection (Hidi, 1990), although individual interest tends to have more enduring effects. Descriptors of interest in learning have included a host of names (e.g., academic, individual, personal, cognitive), which have been used interchangeably to some extent. Earlier research tended to focus on general interest across subjects. However, students often are more interested in some school subjects than in others. Contemporary research has stressed that interest is a domainspecific construct (e.g., Gogol et al., 2017), and that it is necessary to measure interest separately for different school subjects (e.g., math interest, English interest, etc.). The concept of academic interest to which this paper refers represents the individual interest of adolescents related to school tasks, focusing on subjectspecific or subject interest.

\section{Four-Phase Interest Development Model and Constituents of Academic Interest}

Hidi and Renninger (2006) developed a four-phase interest development model based on POI, which is the most complete and widely used model illustrating the essence of academic interest. The first two phases, triggered situational interest and maintained situational interest, are included under situational interest, which is sparked by environmental stimuli and temporary sustained by support from others. The last two phases, emerging individual interest and well-developed individual interest, belong to individual interest, the motivation of which results mainly from individuals themselves and partially from the support of others (Hidi and Renninger, 2006).

Hidi and Renninger (2006) suggested that "each phase of interest is characterized by varying amounts of affect, knowledge, and value." Furthermore, engagement in learning activities differs in each phase. Well-developed individual interest promotes selfregulation and enthusiasm to engage and reengage in learning activities, leading to the individual's persistence when confronted with difficult situations (Hidi and Renninger, 2006). We can, therefore, further divide academic (individual) interest into four components: emotion, value, knowledge, and engagement. The component of emotion refers to the positive feelings accompanying the activities, such as pleasure, excitement and enjoyment (Izard, 1991; Schiefele, 1991; Csikszentmihalyi and Hunter, 2003; Hidi and Renninger, 2006). The component of value refers to the perception of the personal significance of the specific object or domain, such as its importance to individual development (Schiefele, 1991; Krapp, 1999; Hidi and Renninger, 2006). The component of knowledge refers to the perception of stored knowledge in a specific domain. Krapp (2000) suggested that stored knowledge can be used to assess interest due to the positive correlations between them 
(Alexander and Jetton, 1994). The component of engagement refers to the predisposition to participate in specific learning activities. Students who have a high level of individual interest prefer to join in more learning activities (Schiefele, 1991; Tobias, 1994; Mazer, 2013). Meanwhile, engagement can facilitate the sustaining and deepening of interest for specific object or content (e.g., Csikszentmihalyi and Rathunde, 1992; Renninger, 2000; Hidi et al., 2004).

\section{Potential Limitations of the Existing Academic Interest Instruments}

A closer examination of the existing academic interest measures in the Western contexts and Asian has revealed a number of limitations that this study aims to address.

First, there is a need to further develop academic interest scales for adolescents based on the four-phase interest development model. In accordance with different conceptualizations and operationalizations of interest, a variety of academic interest instruments have been used across studies, which involved single, two- or three-components measures. Single component measures use emotion or value as the only indicator of academic interest measures with one or more items (Nurmi and Aunola, 2005; Dotterer et al., 2009; Kalender and Berberoglu, 2009; Viljaranta et al., 2014; Jõgi et al., 2015). Two-component measures included both emotion and value, such as the Study Interest Questionnaire (SIQ, Schiefele et al., 1988) and academic interest scales developed by Linnenbrink-Garcia et al. (2010), Maurice et al. (2014), and Høgheim and Reber (2015). Only a few threecomponent measurements have been developed. In addition to emotion and value, the other component may be knowledge or engagement. For example, the General Individual Interest Scale (GIIS), developed by Tang and Toyama (2016) in Japan, is divided into three subscales (emotion, value, and knowledge) to assess undergraduates' academic interest. Rotgans (2015) developed an individual interest scale for high school students in Singapore. The seven-item scale assessed three aspects of academic interest: positive emotion, value, and predisposition to reengage with particular content.

The four-phase interest development model provides a broader and more comprehensive theoretical framework for the measurement of interest. As mentioned earlier, the construct of academic interest is multidimensional according to the model, including the components of emotion, value, knowledge, and engagement. Four-component measures of academic interest are rare. To the best of our knowledge, only one scale for the subject of math, which used a sample of elementary students, has been developed to date in the U.S. (Wininger et al., 2014). Two Chinese scales, MLIQ and SLIS, adopted the four-phase interest development model. One problem for the two scales is that their dimensions are different phases. MLIQ comprises three dimensions: triggered situational interest, maintained situational interest, and individual interest. SLIS comprises four dimensions: triggered situational interest, maintained situational interest, emerging individual interest and well-developed individual interest. Their dimensions overlap to some extent. For example, emotion may be included in different subscales. Therefore, the development of a new scale for Chinese adolescents based on the essence of academic interest according to four-phase interest development model is justified.

Second, there is a need to further develop interest measures for adolescents that can be generally used in different subjects. Most researchers have held that academic interest differed across subjects (e.g., Schiefele, 1991; Krapp, 2002; Hidi and Renninger, 2006). For example, students hold different levels of interest in biology, chemistry, and physics (Jansen et al., 2016). Students with higher interest in French were found to have a lower interest in German (Gogol et al., 2015). Some subject-specific academic interest scales have assessed interest only in a particular narrowly defined subject, such as math (e.g., Wininger et al., 2014). MLIQ and SLIS are all subject-specific interest scales. MLIQ consists of 17 items such as "I like to inquiry the in and out of mathematical principles and formulas" to assess math interest (Wu and Liu, 2017). SLIS includes items like "I might imitate the actions of my favorite athletes" to assess sports learning interest. As can be seen from the items, it is difficult for other researchers to use these instruments in different domains or subjects. Meanwhile, some empirical research has replaced the name of the domain in items to directly measure certain interest (e.g., Nurmi et al., 2011; Jansen et al., 2016). This approach ignores whether academic interests have the same structure among different subjects. To be able to work across subjects to compare academic interest, parallel scales with equivalent measurement structures and items to measure academic interest in multiple academic subjects for each person are required. Nonetheless, few questionnaires currently exist that have been developed based on this premise. Moreover, to be able to test intraindividual and interindividual differences across subject domains, measurement instruments need to reflect strong measurement invariance across subjects (Meredith, 1993), i.e., scores in one subject need to be comparable to scores in another subject. As far as we know, only one study has been reported in the literature testing measurement invariance across subjects. Rotgans (2015) established the metric invariance of the onefactor interest model across three subjects (chemistry, geography, and history) using a multi-group comparison approach.

Third, there is a need to further test measurement invariance across time, genders, and grades in academic interest instruments. Academic interests are often compared across time. For example, longitudinal research has shown that students' academic interest declines over time (Dotterer et al., 2009; Frenzel et al., 2010). Students' academic interest in math, physics and chemistry subject obviously declines over time most, but their interest in biology has not been shown to decline significantly (Todt et al., 1998). For subjects in science domains, girls' interest declines significantly faster than boys (Hoffmann, 2002). Additionally, gender and grade differences on the mean level in academic interest have also been documented (Koller et al., 2001; Frenzel et al., 2010). Measurement invariance is a prerequisite for comparing these differences. To be able to compare latent means across time, genders and grades, factor loadings and item intercepts must be invariant (Meredith, 1993). If invariance is not given, the differences in observed test scores in different groups or at different times does not necessarily 
reflect true differences. However, measurement invariance of such academic interest scales across time, genders, and grades has been seldom tested. The invariance of the academic interest instruments has not yet been tested in China, as far as we know.

Based on the above, our first objective of the present study was to develop the Academic Interest Scale for Adolescents (AISA) for assessing multiple academic interest facets across school subjects among adolescents in the Chinese education context. Through creating items suitable for different subjects, expert feedback, cognitive interview, exploratory factor analysis (EFA) and confirmatory factor analysis (CFA), we expected to obtain a generic academic interest scale for Chinese adolescents with four-factor latent structure. Our second objective was to preliminarily validate the AISA. We expected to observe adequate internal consistency and satisfactory test-criterion relationships. Our third objective was to test the measure invariance across subjects, time, genders and grades, and expected to observe invariances in measurement and structure.

\section{MATERIALS AND METHODS}

\section{Design}

This study consisted of three cross-sectional questionnaire surveys in three large samples of Chinese junior high school students recruited by cluster sampling. The goal of the first survey was to develop and initially validate the AISA scale in two subjects (math, English). The second survey was to test measurement invariance across time. The third survey was intended to further validate the factorial structure spanning across three subjects (math, English, and Chinese), and tested the measurement invariance across subjects, genders, and grades. The first survey was conducted in September 2017, the second was in November 2017, and the third was in October and November 2018.

\section{Participants Sample 1}

A total of 552 students (45.5\% girls; age: $M=12.31$ years, $S D=0.98$, range $=10-15$ years) were recruited from 12 classrooms in grades 6-8 in two public junior high schools of central China's Henan Province. The only child rate was 29\%. Paternal and maternal education levels were 2.5 and $0.9 \%$ for graduate school and above, 29.7 and $25.7 \%$ for university, 34.4 and $33.9 \%$ for senior high school, and 33.5 and $39.5 \%$ for junior high school and below, respectively. The number of participants in each grade and their gender is shown in Table 1. Among these, 552 participants completed the AISA scale, Intrinsic Motivation Scale (IMS) and Scale for Adolescents' Flow State in Learning (SAFSL) in math and 525 participants completed the same scales in English.

\section{Sample 2}

Two months later, a subgroup of 411 students for math and 396 students for English who participated in the first survey completed the AISA in math and English again. The demographic characteristics were similar to those of the first sample. The data was used to assess measure invariance over time.
TABLE 1 | The number of participants in each grade as well as their gender.

\begin{tabular}{ccccccc}
\hline Subject & Gender & Grade 6 & Grade 7 & Grade 8 & Grade 9 & Total \\
\hline Sample 1 & Boys & 101 & 99 & 101 & - & 301 \\
& Girls & 105 & 76 & 70 & - & 251 \\
& Total & 206 & 175 & 171 & - & 552 \\
Sample 3 & Boys & - & 372 & 330 & 186 & 888 \\
& Girls & - & 337 & 312 & 243 & 892 \\
& Total & - & 709 & 642 & 429 & 1780 \\
\hline
\end{tabular}

\section{Sample 3}

A total of 1,780 students (50.1\% girls; age: $M=13.69$ years, $S D=0.97$, range $=12-16$ years) were recruited from 48 classrooms in grades 7-9 in 13 junior high schools of Beijing, China. The only child rate was $62.3 \%$. Paternal and maternal education levels were 6.9 and $5.3 \%$ for graduate school and above, 29.9 and $30.8 \%$ for university, 38.9 and $40.4 \%$ for senior high school, 23.3 and $22.0 \%$ for junior high school and below, respectively; $1.0 \%$ of the paternal educational level and $1.5 \%$ of the maternal educational level were unknown. All participants completed the AISA scale in math, English, and Chinese. The number of participants in each grade as well as their gender is shown in Table 1.

The experimental protocol and anonymous informed consent were approved by the Ethics Research Committee (ERC) of School of Psychology, Capital Normal University, to protect participants' privacy. Written approval for the research was provided by the principal of each participating school before the data collection occurred. Students participated in the research voluntarily and provided anonymous informed verbal assent. The parents were fully informed of the research purpose and procedure and provided their anonymous verbal informed consents to have their children participate. Written informed consent from the parents was not obtained because the ERC waived this requirement to protect students' anonymity and privacy, as the consent document could link the participant to the research.

\section{Development of Academic Interest Scale for Adolescents (AISA) Item Creation}

The first step in scale construction was to develop linguistic definitions of academic interest and the scope of contents according to the four-phase interest development model through group discussion. The AISA item pool was drawn from the theoretical rationale described above and existing measures of individual interest (e.g., Harackiewicz et al., 2008; Schiefele, 2009; Linnenbrink-Garcia et al., 2010; Wininger et al., 2014; Rotgans, 2015; Tang and Toyama, 2016; Wang and Adesope, 2016; Wu and Liu, 2017). We included as many items as possible in the item pool that were suitable for different subjects for further item/factor selection. A total of 81 items including four domains were initially generated: 23 items for emotion (e.g., "I enjoy studying ..."), 20 items for value (e.g., "The knowledge of ... promotes my growth"), 18 items for knowledge (e.g., "I know all 
kinds of things about ..."), and 20 items for engagement (e.g., "I want to learn things that are not included in ... textbooks"). All items were scored on a five-point Likert scale: 1 represented "strongly disagree," and 5 represented "strongly agree." We used these items with identical wording (except for the name of the subject) to assess individual interest in math, English and Chinese, replacing “...” with "math" or "English" or "Chinese."

\section{Expert Feedback}

Seven experts, including five researchers on educational psychology and two junior high school teachers, were invited to review the items. The experts received our definition of academic interest and a rationale for scale development. They were asked first to rate whether each item clearly assessed defined content using a five-point Likert scale ranging from strongly disagree to strongly agree. Means and standard deviations were calculated. All items ranked above three and were kept. The experts were also asked to modify the items if they thought there was something inappropriate (e.g., not easy to understand; not fit for different school subjects) and add new items to include the entire scope of academic interest based on their experience. Two authors revised the items according to the experts' suggestions. For example, in Item 37, the word "relaxed" was replaced with "excited." Fifteen items were amended, and no new items were added.

\section{Cognitive Interview}

Cognitive interviews examining the 81 items in the draft were conducted with a convenience sample of six junior high school students. The items were divided into three approximately equal parts. Each participant completed one part, and each part was completed by two participants. Three graduate research assistants administered items to participants, asked them to explain their understanding of each item and corresponding response options, and noted items that participants perceived as confusing or unclear. Interviews lasted between 40 and $60 \mathrm{~min}$ and were audiorecorded. Based on feedback obtained from the interviews, minor wording changes were made to four items. As a result, a total of 81 items were generated for pilot study.

\section{Other Instruments}

\section{Intrinsic Motivation Scale (IMS)}

Served as one of the criterion measures, the IMS (Elliot and Church, 1997; Wang et al., 2006) was used to assess participants' intrinsic motivation toward their math/English class. This scale includes eight items using a five-point Likert scale (from strongly disagree to strongly agree). Internal consistency in both subjects (composite reliability $=0.88$ and 0.85 ) was acceptable in this study.

\section{Scale for Adolescents' Flow State in Learning (SAFSL)}

Served as one of the criterion measures, the SAFSL (Lei et al., 2012) was used to assess participants' flow state when they become engaged in math/English learning. This scale includes 12 items on four dimensions (definite goals of learning, concentration on task and enjoyment, loss of self-consciousness and distortion of time perception). Participants used 1 (never happened) to 5 (always happened) scales to indicate their responses. Internal consistency for the entire scale and subscales in both subjects were adequate in this study. For the entire scale, the composite reliability was 0.95 in math and 0.96 in English. For each of the subscales the composite reliability was 0.76 , $0.87,0.82,0.73$ respectively in math, and $0.86,0.92,0.86,0.77$ respectively in English.

\section{Statistical Analyses}

The data analysis was performed with Mplus 7.0 (Muthén and Muthén, 2012). The percentage of missing data among items was $1.2 \%$ in sample $1,1.0 \%$ in sample 2 , and $0.3 \%$ in sample 3. Little's MCAR test was conducted, and all the missing data in the different subjects of the three samples were confirmed to be missing completely at random $\left(387.21 \leq \chi^{2} s \leq 9505.94\right.$, $456 \leq d f s \leq 9545$, $p s \geq 0.47)$. Meanwhile, the mean values of all items ranged from 1.62 to 4.46 . The standard deviations ranged from 0.79 to 1.35 . The skew and kurtosis indices ranged from -1.55 to 1.79 and from -1.12 to 2.42 , respectively. Following Kline's (2005) recommendations, the data in this study were considered to be univariate normal. We used the full-information maximum likelihood estimation (FLML) implemented in Mplus 7.0 to address missing values, which utilize all available information when estimating the model parameters (Schafer and Graham, 2002).

An EFA for math in sample 1 was conducted to refine the scale and determine the factorial structure using principle axis factoring and promax rotation. CFAs for math, English, and Chinese in sample 3 were conducted separately to examine the factorial structure of the scale using maximum likelihood (ML). We assessed the model fit using multiple indices: the comparative fit index (CFI), the Tucker-Lewis index (TLI), the root mean square error of approximation (RMSEA), and the standardized root mean square residual (SRMR). CFI and TLI values greater than 0.90 (Hu and Bentler, 1999), SRMR values less than 0.08 (Hu and Bentler, 1999), and RMSEA values less than 0.08 (Mcdonald and Ho, 2002) are considered to indicate adequate model fits to the data, respectively. However, it should be noted that these criteria are arbitrary (Hu and Bentler, 1999; Hau et al., 2004). Additionally, chi-square to the degrees of freedom $\left(\chi^{2} / \mathrm{df}\right)$ values less than 5 are considered to indicate an excellent model fit (Kline, 2005). Given the actually large sample size, fit should not be over-interpreted.

The internal consistency for the AISA and each of the subscale was assessed using composite reliability and the Cronbach's $\alpha$ in sample 1 . Composite reliability and the Cronbach's $\alpha$ greater than 0.70 indicate adequate homogeneity (Nunnally and Bernstein, 1994). The test-criterion relationships were assessed using bivariate correlations between academic interest evaluated by the AISA and intrinsic motivation and flow state in learning in sample 1 .

Tests of measurement invariance were used to determine whether the measurement structure is consistent across time (sample 2) and across subjects, genders, and grades (sample 3 ). We conducted the tests across academic subjects by specifying the latent factors in different subjects as separate factors and 
tests across time, subjects, genders, and grades by using multiplegroup analyses within the CFA framework. In accordance with the steps outlined by Meredith (1993) and Vandenberg and Lance (2000), a series of nested models with increasing invariance restrict were conducted. Before these tests, we reported the goodness of fit for the models separately in different subjects, time, genders, and grades to ensure each of them was reasonable. Then, four models were performed successively. Model 1 was a configural invariance model with identical loading patterns but no invariance for any parameters. Model 2 was a metric invariance (weak invariance) model with factor loadings constrained to invariant across subjects, time, genders, and grades. Model 3 was a scale invariance (strong invariance) model with additionally constrained item intercepts to be equality across subjects, time, genders, and grades. Model 4 was a structural invariance model with factor variances and covariances (in addition to invariant factor loadings and item intercepts) constrained to equality across subjects, time, gender, and grades.

The fit of the constrained model and the unconstrained model were compared in terms of their $\chi^{2}$ values. A nonsignificant increase in the $\chi^{2}$ value (relative to $d f$ ) in the constrained model compared to the unconstrained model indicated that the constrains across groups were possible. As an additional criterion, the change in the CFI coefficient was considered. If the decrease in CFI value of the constrained model compared to the unconstrained model was more than 0.01 ( $\Delta \mathrm{CFI}<-0.01$ ), the constrained model was not supported, which indicate a lack of invariance. The $\Delta$ CFI criterion was argued to be superior to $\Delta \chi^{2}$, as it is less sensitive to sample size (Cheung and Rensvold, 2002). Configural invariance means that the pattern of factors is equivalent across subjects, time, genders, and grades (Horn and Mcardle, 1992). Metric invariance (invariant factor loadings) implies equality of scaling units across subjects, time, genders, and grades (Cole and Maxwell, 1985; Marsh, 1994). Scalar invariance (invariant intercepts) implies that intercepts of items' regressions on the factor are invariant across subjects, time, genders, and grades (Meredith, 1993). Finally, structural invariance (invariant factor variance and covariances) represents that differences in factor variances and covariances are interpreted as reflecting differences in the calibration of true scores and in conceptual associations among the true scores across subjects, time, genders, and grades (Schmitt, 1982).

\section{RESULTS}

\section{Exploratory Factor Analysis (EFA)}

Because math is a main subject for Chinese students and the AISA for math was implemented in all three surveys, we first conducted an EFA using principle axis factoring and promax rotation on the 81 items for math in sample 1 to determine the factorial structure of the AISA scale. We used parallel analysis (Horn, 1965) to determine the number of factors to retain, which is considered a more accurate criterion compared with eigenvalues greater than 1 and the scree test (Hayton et al., 2004). Fifty randomly generated simulated data sets indicated 95\% confidence intervals (CIs) of 1.851-1.874, 1.781-1.796, 1.705$1.758,1.700-1.712$, and $1.665-1.674$ for the eigenvalue of the first five random factors, respectively. In the actual data set, only the factors with eigenvalues greater than the upper limit of these CIs would be retained. A four-factor model was supported.

Four items with item-total correlations of less than 0.30 were removed after item analysis. Furthermore, all items with loadings of 0.30 and lower were also removed from further analysis (Nunnally and Bernstein, 1994). Ultimately, 52 items in math models were excluded based on lower factor loadings, crossed loadings (loading greater than 0.30 in two or more factors), and item analysis statistics. A 29-item scale was generated. The eigenvalues of the four factors were 15.093, 1.763, 1.158, and 1.013, respectively. The latent variables explained 13.29, 10.56, 9.45 , and $7.30 \%$ of variance, respectively, and together explained $59.40 \%$ of the total variance. Interfactor correlations ranged from 0.59 to 0.67 . The factors were labeled as emotion, value, knowledge, and engagement. Specifically, the emotion, value and engagement subscales consisted of seven items each, whereas the knowledge subscale included eight items. The final items in English and Chinese are described in the Appendix. Factor loadings and item-total correlations can be seen in Table 2 .

\section{Confirmatory Factor Analyses (CFAs)}

To further verify the factorial structure of the 29-item AISA, CFAs for four-factor models in math, English, and Chinese subjects (sample 3 ) were computed separately. Model fits were all acceptable (Table 3). In sample 3, all factor loadings of math ranged from 0.492 to 0.814 . For English, factor loadings ranged from 0.546 to 0.825 . For Chinese, factor loadings ranged from 0.464 to 0.811 (Table 2).

\section{Tests of the Internal Consistency}

Based on the data from the first survey $\left(\mathrm{N}_{\text {math-1 }}=552\right.$; $\mathrm{N}_{\text {English-1 }}=525$ ), the composite reliability (CR) and Cronbach's alpha values indicated that the AISA and each subscale were internally consistent. For the total AISA, the CR was 0.98 and $\alpha$ was 0.80 in math, the CR was 0.98 and $\alpha$ was 0.83 in English. For the emotion, value, knowledge, and engagement subscale, the CR was $0.80,0.91,0.88,0.86$ and $\alpha$ was $0.87,0.90,0.88,0.86$ in math, the CR was $0.80,0.93,0.93,0.91$ and $\alpha$ was $0.90,0.93,0.93$, 0.91 in English.

\section{Tests of Test-Criterion Relationships}

Within the sample from the first survey $\left(\mathrm{N}_{\text {math-1 }}=552\right.$; $\mathrm{N}_{\text {English-1 }}=525$ ), bivariate correlations indicated satisfactory test-criterion relationships between the AISA and intrinsic motivation and flow state in learning, respectively. For math, the AISA total score had strong, significant positive correlations with the intrinsic motivation and the flow state in learning, correlations coefficients were 0.95 and 0.87 ( $p s<0.001$ ). For English, the AISA total score had moderate, significant positive correlations with the intrinsic motivation and the flow state in learning, correlations coefficients were 0.51 and 0.60 ( $p s<0.001$ ). 


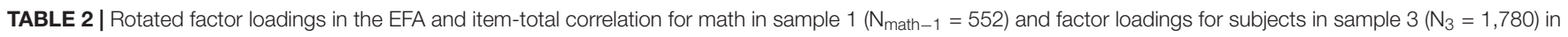
the CFA.

\begin{tabular}{|c|c|c|c|c|c|c|c|c|}
\hline \multirow[b]{2}{*}{ Item } & \multicolumn{4}{|c|}{ EFA } & \multirow{2}{*}{$\begin{array}{l}\text { Item-total } \\
\text { correlation }\end{array}$} & \multicolumn{3}{|c|}{ CFA } \\
\hline & 1 & 2 & 3 & 4 & & Math-3 & English-3 & Chinese-3 \\
\hline 3 & 0.675 & 0.134 & 0.052 & 0.080 & 0.806 & 0.760 & 0.746 & 0.741 \\
\hline 5 & 0.592 & 0.037 & 0.146 & 0.163 & 0.806 & 0.797 & 0.800 & 0.755 \\
\hline 8 & 0.673 & 0.090 & 0.122 & 0.058 & 0.808 & 0.796 & 0.807 & 0.793 \\
\hline 13 & 0.542 & 0.101 & 0.050 & 0.215 & 0.782 & 0.797 & 0.785 & 0.762 \\
\hline 14 & 0.622 & 0.084 & 0.096 & 0.142 & 0.808 & 0.806 & 0.825 & 0.811 \\
\hline 18 & 0.561 & 0.111 & 0.196 & 0.045 & 0.788 & 0.774 & 0.799 & 0.793 \\
\hline 26 & 0.687 & 0.095 & 0.067 & 0.103 & 0.817 & 0.805 & 0.785 & 0.742 \\
\hline 1 & -0.012 & 0.648 & 0.165 & -0.117 & 0.593 & 0.582 & 0.636 & 0.573 \\
\hline 10 & 0.033 & 0.488 & 0.140 & 0.056 & 0.629 & 0.606 & 0.656 & 0.629 \\
\hline 16 & -0.048 & 0.728 & -0.058 & 0.165 & 0.675 & 0.698 & 0.721 & 0.670 \\
\hline 17 & 0.046 & 0.504 & 0.016 & 0.174 & 0.645 & 0.740 & 0.753 & 0.732 \\
\hline 20 & -0.001 & 0.602 & 0.218 & 0.003 & 0.708 & 0.782 & 0.793 & 0.794 \\
\hline 24 & 0.105 & 0.799 & -0.092 & 0.015 & 0.705 & 0.769 & 0.789 & 0.769 \\
\hline 27 & 0.037 & 0.804 & -0.031 & -0.001 & 0.688 & 0.814 & 0.819 & 0.802 \\
\hline 29 & 0.052 & 0.745 & 0.005 & 0.010 & 0.695 & 0.803 & 0.798 & 0.786 \\
\hline 4 & 0.042 & 0.036 & 0.561 & 0.054 & 0.615 & 0.652 & 0.681 & 0.616 \\
\hline 7 & 0.299 & 0.032 & 0.612 & -0.163 & 0.686 & 0.750 & 0.765 & 0.686 \\
\hline 9 & 0.174 & 0.025 & 0.569 & 0.043 & 0.704 & 0.761 & 0.763 & 0.680 \\
\hline 12 & 0.120 & 0.071 & 0.422 & 0.265 & 0.758 & 0.782 & 0.781 & 0.742 \\
\hline 15 & 0.118 & -0.036 & 0.510 & 0.145 & 0.646 & 0.710 & 0.716 & 0.675 \\
\hline 22 & -0.042 & -0.025 & 0.648 & 0.195 & 0.674 & 0.733 & 0.757 & 0.725 \\
\hline 23 & -0.115 & -0.006 & 0.767 & 0.111 & 0.657 & 0.752 & 0.759 & 0.719 \\
\hline 2 & -0.018 & 0.020 & 0.072 & 0.620 & 0.617 & 0.492 & 0.546 & 0.464 \\
\hline 6 & 0.264 & 0.181 & 0.003 & 0.484 & 0.800 & 0.708 & 0.761 & 0.715 \\
\hline 11 & 0.043 & -0.059 & 0.190 & 0.621 & 0.696 & 0.659 & 0.725 & 0.664 \\
\hline 19 & 0.155 & 0.106 & 0.019 & 0.607 & 0.763 & 0.787 & 0.782 & 0.793 \\
\hline 21 & -0.014 & -0.005 & 0.133 & 0.398 & 0.480 & 0.517 & 0.609 & 0.529 \\
\hline 25 & 0.033 & 0.237 & 0.092 & 0.309 & 0.594 & 0.633 & 0.615 & 0.582 \\
\hline 28 & 0.230 & 0.168 & 0.115 & 0.357 & 0.756 & 0.742 & 0.757 & 0.736 \\
\hline
\end{tabular}

EFA, exploratory factor analysis; CFA, confirmatory factor analysis. The bold values mean items with a strong loading (0.30 or higher) on one factor.

TABLE 3 | Model fit statistics for CFA in sample $3(N=1,780)$.

\begin{tabular}{llllllll}
\hline Model & $\chi^{2}$ & $d f$ & CFI & TLI & SRMR & $\begin{array}{l}\text { RMSEA } \\
(90 \% \mathrm{Cl})\end{array}$ & $\begin{array}{c}\text { Total of } \\
\text { items }\end{array}$ \\
\hline
\end{tabular}

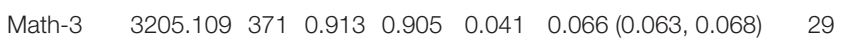

$\begin{array}{lllllllll}\text { English-3 } & 2890.026 & 371 & 0.927 & 0.920 & 0.037 & 0.062(0.060,0.064) & 29\end{array}$

$\begin{array}{llllllll}\text { Chinese-3 } & 3058.911 & 371 & 0.910 & 0.901 & 0.041 & 0.064(0.062,0.066) & 29\end{array}$

$\chi^{2}$, chi-square; $d f$, the degrees of freedom; CFI, comparative fit index; TLI, TuckerLewis index; SRMR, standardized root mean square residual; RMSEA, root mean square error of approximation; $\mathrm{Cl}$, confidence interval.

\section{Tests of Measurement Invariance Across Academic Subjects}

Using the data from sample 3, we examined four levels of invariance (configural invariance, metric invariance, scalar invariance, and structural invariance) between math, English, and Chinese subject. As shown in Table 4, configural invariance with no further constraints was supported by fit indices meeting benchmarks for adequate fit, $\chi^{2} / d f=8.225, \mathrm{CFI}=0.917, \mathrm{TLI}=0.909, \mathrm{SRMR}=0.039$, RMSEA $=0.064 \quad(0.063,0.065)$. Metric, scalar, and structural invariance could be assumed between math and English subjects, as evidenced by a non-significant drop in model fit $(\Delta \mathrm{CFI}>-0.01)$ for the successively stricter models.

\section{Tests of Measurement Invariance Over Time}

As a requirement for comparison over time, we examined four levels of invariance (configural invariance, metric invariance, scalar invariance, and structural invariance) over time in math and English subject separately in sample 2. The test of the configural invariance model with no further constraints resulted in an adequate fit to the data in two subjects, for math, $\chi^{2} / d f=1.944, \mathrm{CFI}=0.918, \mathrm{TLI}=0.912, \mathrm{SRMR}=0.038$, RMSEA $=0.048(0.045,0.050)$; for English, $\chi^{2} / d f=2.019, \mathrm{CFI}=$ $0.926, \mathrm{TLI}=0.920, \mathrm{SRMR}=0.039, \mathrm{RMSEA}=0.051(0.048,0.053)$. The models for test metric, scalar, and structural invariance had 
TABLE 4 | Model fit statistics for models representing different degrees of invariance across academic subjects $(N=1,780)$.

\begin{tabular}{|c|c|c|c|c|c|c|c|c|c|}
\hline Model & $x^{2}$ & $d f$ & $\Delta \chi^{2}$ & $\Delta d f$ & CFI & TLI & SRMR & RMSEA $(90 \% \mathrm{Cl})$ & $\Delta \mathrm{CFI}$ \\
\hline Math & 3205.11 & 371 & - & - & 0.913 & 0.905 & 0.041 & $0.066(0.063,0.068)$ & \\
\hline English & 2890.03 & 371 & - & - & 0.927 & 0.920 & 0.037 & $0.062(0.060,0.064)$ & \\
\hline Chinese & 3058.91 & 371 & - & - & 0.910 & 0.901 & 0.041 & $0.064(0.062,0.066)$ & \\
\hline Configural invariance & 9154.045 & 1113 & - & - & 0.917 & 0.909 & 0.039 & $0.064(0.063,0.065)$ & \\
\hline Metric invariance & 9233.031 & 1163 & $78.986^{* *}$ & 50 & 0.917 & 0.913 & 0.042 & $0.062(0.061,0.064)$ & 0.000 \\
\hline Scalar invariance & 9789.602 & 1213 & $556.571^{* * *}$ & 50 & 0.912 & 0.911 & 0.045 & $0.063(0.062,0.064)$ & -0.005 \\
\hline Structural invariance & 9844.775 & 1233 & $55.173^{* * *}$ & 20 & 0.911 & 0.912 & 0.059 & $0.063(0.061,0.064)$ & -0.001 \\
\hline
\end{tabular}

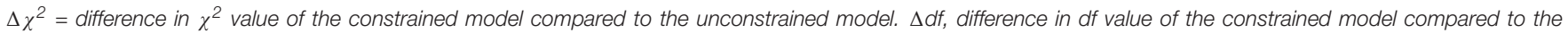
unconstrained model. $\Delta \mathrm{CFI}$, difference in CFI value of the constrained model compared to the unconstrained model. ${ }^{* *} p<0.01,{ }^{* * *} p<0.001$.

no substantial changes in model fit $(\Delta \mathrm{CFI}>-0.01)$, indicating that metric, scalar, and structural invariance held over time for both academic subjects (Table 5).

\section{Tests of Measurement Invariance Across Genders}

We examined measurement invariance across students' genders for the three subjects separately in sample 3. As shown in Table 6, the test of the configural invariance model with no further constraints was supported in three subjects, for math, $\chi^{2} / d f=4.900$, CFI $=0.912$, TLI $=0.904$, SRMR $=0.044$, RMSEA $=0.066(0.064,0.068)$; for English, $\chi^{2} / d f=4.565$, $\mathrm{CFI}=0.922$, TLI $=0.915, \mathrm{SRMR}=0.040, \mathrm{RMSEA}=0.063(0.061$, 0.065); for Chinese, $\chi^{2} / d f=4.583, \mathrm{CFI}=0.911$, TLI $=0.902$, SRMR $=0.043$, RMSEA $=0.063(0.061,0.066)$. Metric, scalar, and structural invariance could be assumed across genders in three subjects, as evidenced by a non-significant drop in model fit $(\Delta \mathrm{CFI}>-0.01)$ for the successively stricter models.

\section{Tests of Measurement Invariance Across Grades}

We also tested measurement invariance across grade levels (Grades 7, 8, and 9) in sample 3. Analysis program was the same as previous. As shown in Table 7, the test of the configural invariance model with no further constraints was supported in three subjects, for math, $\chi^{2} / d f=3.468, \mathrm{CFI}=0.918$, TLI $=0.909$, SRMR $=0.043$, RMSEA $=0.064(0.062,0.067)$; for English, $\chi^{2} / d f=3.479$, CFI $=0.920$, TLI $=0.912$, SRMR $=0.041$, RMSEA $=0.065(0.062,0.067)$; for Chinese, $\chi^{2} / d f=3.487$, $\mathrm{CFI}=0.910, \mathrm{TLI}=0.900, \mathrm{SRMR}=0.045, \mathrm{RMSEA}=0.065$ $(0.063,0.067)$. Metric, scalar and structural invariance could be held across grades in three subjects, as evidenced by a nonsignificant drop in model fit $(\Delta \mathrm{CFI}>-0.01)$ for the successively stricter models.

\section{DISCUSSION}

The current study developed and validated the Academic Interest Scale for adolescents (AISA), a new instrument for academic interest with more than 2,300 adolescents in the Chinese education context. The final scale contains 29 items and four factors, that is, emotion, value, knowledge, and engagement. This scale can generically be used for diverse subjects across different educational settings.

Hidi and Renninger's four-phase interest development model is the most complete extant model based on the existing interest literature. Some researchers in the U.S. have developed math interest measures for elementary students according to this model (e.g., Wininger et al., 2014). Four-factor construct was obtained. Previous studies in China have developed two subject-specific interest scales (MLIQ, Wu and Liu, 2017; SLIS, Lin and Chai, 2017) for elementary and middle school students based on this model as well. But it is worth bearing in mind that the scales applied different phases as subscales instead of exploring the essence of interest. The AISA is different from the existing instruments in that it was (1) devised based on the structure and content of academic interest and the four-phase interest development model and (2) suitable for different subjects for Chinese adolescents.

Expert feedback and cognitive interview were used to initially select and modify the items in the item generation phase. EFA was conducted on the subject of math in sample 1 to refine the scale and determine factorial structure. Using a large sample $(N=552)$, we dropped more than half (52 items) of the initial items because of poor factor loading and the item discrimination index. Meanwhile, CFAs were conducted on math, English, and Chinese in sample $3(N=1,780)$ to further test the model fit of a 29-item scale. All indices except the $\chi^{2} / d f$ met the recommended thresholds for an adequate fit. The high value of the $\chi^{2} / d f$ was likely related to the large sample size. These results suggested that a fourfactor model can appropriately capture the complex structure of academic interest in math, English, and Chinese subject in Chinese adolescents. Among these four factors, emotion means the extent to which a student has positive emotional response to targeted academic subject, such as liking, excitement and enjoyment. Value means the degree to which a student thinks that learning targeted subject is important, meaningful or useful. Knowledge means the level of stored knowledge for related-subject a student perceived. Engagement means the extent to which a student engages and reengages specific academic activities, events, and ideas over time. These findings extend prior studies which manifested four-factor structure of academic interest in elementary students in the U.S. (e.g., Wininger et al., 2014), by showing the similar structure in junior 
TABLE 5 | Model fit statistics for models representing different degrees of invariance over time $\left(N_{\text {math }}=411 ; N_{\text {English }}=396\right)$.

\begin{tabular}{|c|c|c|c|c|c|c|c|c|c|}
\hline Model & $x^{2}$ & $d f$ & $\Delta \chi^{2}$ & $\Delta d f$ & CFI & TLI & SRMR & RMSEA $(90 \% \mathrm{Cl})$ & $\Delta \mathrm{CFI}$ \\
\hline \multicolumn{10}{|l|}{ Math } \\
\hline Time 1 & 772.700 & 371 & - & - & 0.948 & 0.943 & 0.037 & $0.051(0.046,0.056)$ & \\
\hline Time 2 & 1139.448 & 371 & - & - & 0.916 & 0.908 & 0.041 & $0.071(0.066,0.076)$ & \\
\hline Configural invariance & 2989.698 & 1538 & - & - & 0.918 & 0.912 & 0.038 & $0.048(0.045,0.050)$ & \\
\hline Metric invariance & 3026.801 & 1563 & 37.103 & 25 & 0.917 & 0.913 & 0.042 & $0.048(0.045,0.050)$ & -0.001 \\
\hline Scalar invariance & 3130.287 & 1588 & $103.48^{* * *}$ & 25 & 0.913 & 0.909 & 0.043 & $0.049(0.046,0.051)$ & -0.004 \\
\hline Structural invariance & 3159.186 & 1598 & $28.899^{* *}$ & 10 & 0.912 & 0.909 & 0.045 & $0.049(0.046,0.051)$ & -0.001 \\
\hline \multicolumn{10}{|l|}{ English } \\
\hline Time 1 & 1014.022 & 371 & - & - & 0.934 & 0.928 & 0.041 & $0.066(0.061,0.071)$ & \\
\hline Time 2 & 1070.683 & 371 & - & - & 0.933 & 0.926 & 0.037 & $0.069(0.064,0.074)$ & \\
\hline Configural invariance & 3105.249 & 1538 & - & - & 0.926 & 0.920 & 0.039 & $0.051(0.048,0.053)$ & \\
\hline Metric invariance & 3144.131 & 1563 & $38.882^{*}$ & 25 & 0.925 & 0.921 & 0.043 & $0.051(0.048,0.053)$ & -0.001 \\
\hline Scalar invariance & 3244.763 & 1588 & $100.632^{* * *}$ & 25 & 0.922 & 0.918 & 0.045 & $0.051(0.049,0.054)$ & -0.003 \\
\hline Structural invariance & 3262.186 & 1598 & 17.423 & 10 & 0.921 & 0.919 & 0.046 & $0.051(0.049,0.054)$ & -0.001 \\
\hline
\end{tabular}

${ }^{*} p<0.05,{ }^{* *} p<0.01$, and ${ }^{* * *} p<0.001$

TABLE 6 | Model fit statistics for models representing different degrees of invariance across genders $(N=1,780)$.

\begin{tabular}{|c|c|c|c|c|c|c|c|c|c|}
\hline Model & $x^{2}$ & $d f$ & $\Delta \chi^{2}$ & $\Delta d f$ & CFI & TLI & SRMR & RMSEA $(90 \% \mathrm{Cl})$ & $\Delta \mathrm{CFI}$ \\
\hline \multicolumn{10}{|l|}{ Math } \\
\hline Boys & 1902.956 & 370 & - & - & 0.910 & 0.901 & 0.043 & $0.068(0.065,0.071)$ & \\
\hline Girls & 1716.869 & 370 & - & - & 0.915 & 0.907 & 0.042 & $0.064(0.061,0.067)$ & \\
\hline Configural invariance & 3630.968 & 741 & - & - & 0.912 & 0.904 & 0.044 & $0.066(0.064,0.068)$ & \\
\hline Metric invariance & 3657.092 & 765 & 26.124 & 24 & 0.912 & 0.906 & 0.046 & $0.065(0.063,0.067)$ & 0.000 \\
\hline Scalar invariance & 3731.893 & 790 & $74.801^{* * *}$ & 25 & 0.910 & 0.908 & 0.047 & $0.065(0.063,0.067)$ & -0.002 \\
\hline Structural invariance & 3755.034 & 800 & $23.141^{*}$ & 10 & 0.910 & 0.909 & 0.053 & $0.064(0.062,0.067)$ & 0.000 \\
\hline \multicolumn{10}{|l|}{ English } \\
\hline Boys & 1920.749 & 371 & - & - & 0.914 & 0.906 & 0.041 & $0.069(0.066,0.072)$ & \\
\hline Girls & 1470.427 & 371 & - & - & 0.931 & 0.924 & 0.038 & $0.058(0.055,0.061)$ & \\
\hline Configural invariance & 3391.443 & 743 & - & - & 0.922 & 0.915 & 0.040 & $0.063(0.061,0.065)$ & \\
\hline Metric invariance & 3425.393 & 767 & 33.950 & 24 & 0.922 & 0.917 & 0.042 & $0.062(0.060,0.065)$ & 0.000 \\
\hline Scalar invariance & 3454.017 & 792 & 28.624 & 25 & 0.921 & 0.920 & 0.043 & $0.061(0.059,0.064)$ & -0.001 \\
\hline Structural invariance & 3508.579 & 802 & $54.562^{* * *}$ & 10 & 0.920 & 0.919 & 0.081 & $0.062(0.059,0.064)$ & -0.001 \\
\hline \multicolumn{10}{|l|}{ Chinese } \\
\hline Boys & 1690.819 & 366 & - & - & 0.910 & 0.900 & 0.045 & $0.064(0.061,0.067)$ & \\
\hline Girls & 1691.285 & 371 & - & - & 0.913 & 0.904 & 0.041 & $0.063(0.060,0.066)$ & \\
\hline Configural invariance & 3382.331 & 738 & - & - & 0.911 & 0.902 & 0.043 & $0.063(0.061,0.066)$ & \\
\hline Metric invariance & 3415.148 & 762 & 32.817 & 24 & 0.911 & 0.905 & 0.045 & $0.063(0.060,0.065)$ & 0.000 \\
\hline Scalar invariance & 3488.201 & 787 & $73.053^{* * *}$ & 25 & 0.909 & 0.907 & 0.047 & $0.062(0.060,0.064)$ & -0.002 \\
\hline Structural invariance & 3511.186 & 797 & $22.985^{*}$ & 10 & 0.909 & 0.907 & 0.055 & $0.062(0.060,0.064)$ & 0.000 \\
\hline
\end{tabular}

${ }^{*} p<0.05,{ }^{* * *} p<0.001$.

high school students in China. More broadly, these findings support the cross-culture compatibility of the four-phase interest development model.

Meanwhile, the scale scores exhibited satisfactory psychometric properties in terms of internal reliability and test-criterion relationships in math and English subjects. The composite reliability and the Cronbach's $\alpha$ for the total AISA and four subscales were well above the criterion $(>0.70)$ for adequate homogeneity (Nunnally and Bernstein, 1994). Academic interest is recognized as an important source of intrinsic motivation and flow state in learning among students
(Deci, 2010; Shernoff et al., 2014). In this study, the AISA scores showed significant associations with intrinsic motivation and flow state in learning, indicating acceptable test-criterion relationships. The AISA scales had relatively poorer test-criterion relationships with flow state in learning than with intrinsic motivation. This discrepancy is probably because academic interest shares more similarity with intrinsic motivation. More suitable criterion measures should be employed in future research.

This study aimed at developing an academic interest scale suitable for interest comparison in different educational contexts, 
TABLE 7 | Model fit statistics for models representing different degrees of invariance across grades $(N=1,780)$.

\begin{tabular}{|c|c|c|c|c|c|c|c|c|c|}
\hline Model & $x^{2}$ & $d f$ & $\Delta \chi^{2}$ & $\Delta d f$ & CFI & TLI & SRMR & RMSEA $(90 \% \mathrm{Cl})$ & $\Delta \mathrm{CFI}$ \\
\hline \multicolumn{10}{|l|}{ Math } \\
\hline Grade 7 & 1267.097 & 371 & - & - & 0.930 & 0.923 & 0.037 & $0.058(0.055,0.062)$ & \\
\hline Grade 8 & 1381.649 & 366 & - & - & 0.910 & 0.900 & 0.046 & $0.066(0.062,0.069)$ & \\
\hline Grade 9 & 1152.385 & 359 & - & - & 0.911 & 0.900 & 0.046 & $0.072(0.067,0.076)$ & \\
\hline Configural invariance & 3801.130 & 1096 & - & - & 0.918 & 0.909 & 0.043 & $0.064(0.062,0.067)$ & \\
\hline Metric invariance & 3883.162 & 1146 & $82.032^{* *}$ & 50 & 0.917 & 0.912 & 0.049 & $0.063(0.061,0.066)$ & -0.001 \\
\hline Scalar invariance & 3953.980 & 1196 & $70.818^{*}$ & 50 & 0.916 & 0.915 & 0.050 & $0.062(0.060,0.065$ & -0.001 \\
\hline Structural invariance & 4035.989 & 1216 & $82.009^{* * *}$ & 20 & 0.915 & 0.914 & 0.066 & $0.063(0.060,0.065)$ & -0.001 \\
\hline \multicolumn{10}{|l|}{ English } \\
\hline Grade 7 & 1294.899 & 371 & - & - & 0.928 & 0.921 & 0.038 & $0.059(0.056,0.063)$ & \\
\hline Grade 8 & 1365.456 & 371 & - & - & 0.919 & 0.911 & 0.040 & $0.065(0.061,0.068)$ & \\
\hline Grade 9 & 1204.701 & 369 & - & - & 0.910 & 0.901 & 0.046 & $0.073(0.068,0.077)$ & \\
\hline Configural invariance & 3865.057 & 1111 & - & - & 0.920 & 0.912 & 0.041 & $0.065(0.062,0.067)$ & \\
\hline Metric invariance & 3918.209 & 1161 & 53.152 & 50 & 0.920 & 0.916 & 0.045 & $0.063(0.061,0.065)$ & 0.000 \\
\hline Scalar invariance & 3989.891 & 1211 & $71.682^{*}$ & 50 & 0.919 & 0.919 & 0.047 & $0.062(0.060,0.064)$ & -0.001 \\
\hline Structural invariance & 4035.464 & 1231 & $45.573^{* *}$ & 20 & 0.919 & 0.920 & 0.062 & $0.062(0.060,0.064)$ & 0.000 \\
\hline \multicolumn{10}{|l|}{ Chinese } \\
\hline Grade 7 & 1380.599 & 371 & - & - & 0.910 & 0.902 & 0.043 & $0.062(0.058,0.065)$ & \\
\hline Grade 8 & 1288.162 & 369 & - & - & 0.916 & 0.907 & 0.043 & $0.062(0.059,0.066)$ & \\
\hline Grade 9 & 1170.025 & 361 & - & - & 0.901 & 0.888 & 0.049 & $0.072(0.068,0.077)$ & \\
\hline Configural invariance & 3838.785 & 1101 & - & - & 0.910 & 0.900 & 0.045 & $0.065(0.063,0.067)$ & \\
\hline Metric invariance & 3893.812 & 1151 & 55.027 & 50 & 0.910 & 0.904 & 0.049 & $0.063(0.061,0.066)$ & 0.000 \\
\hline Scalar invariance & 3958.217 & 1201 & 64.405 & 50 & 0.909 & 0.908 & 0.050 & $0.062(0.060,0.064)$ & -0.001 \\
\hline Structural invariance & 4033.748 & 1221 & $75.531^{* * *}$ & 20 & 0.907 & 0.908 & 0.062 & $0.062(0.060,0.064)$ & -0.002 \\
\hline
\end{tabular}

${ }^{*} p<0.05,{ }^{* *} p<0.01$, and ${ }^{* * *} p<0.001$.

such as for different school subjects and measure occasions, with different student populations. To this end, we created the items that did not describe the unique content of a specific subject and dropped unexpected items when we conducted the EFA on math. However, proving that the functions of scale are the same in different measuring situations and the measures can be used for mean comparison were not enough (Vandenberg and Lance, 2000). In this study, we also confirmed the metric, scalar, and structural invariance of four-factor model of AISA across subjects (math, English, and Chinese), time, genders, and grade levels. Given that chi-square square difference $\left(\Delta \chi^{2}\right)$ test is sensitive to sample size, we inferred measurement invariance across groups mainly based on CFI difference ( $\Delta$ CFI) (Cheung and Rensvold, 2002). This approach provided stronger evidence for commonality of the AISA across subjects and proved the comparability across academic interest in math, English and Chinese, in boys and girls, in different grade levels and in different measures of time more strictly. Measurement invariances also strengthened the validity of the AISA, which implied that differences in observed test scores in different education settings could reflect true differences in academic interest rather than an artifact of the measurement method.

This study has some limitations. Our sample, adolescents from Chinese junior high schools, may limit the generalizability of the findings. Further studies should test the four-factor interest model of the AISA using larger and multiple samples, including younger children, older adolescents or even the group of adult students. Meanwhile, future studies should examine the factorial invariance of the AISA across different racial/ethnic and language groups. Another possible limitation is that correlated samples (i.e., data of math, English, and Chinese came from the same group students) were used to test the measurement invariance across different subjects. This approach may overestimate the interdisciplinary invariance of the AISA. Independent samples should be used in further test of invariance across academic subjects. The AISA was only administered for math, English, and Chinese in this study. In the future, more diverse domains (e.g., history, biology, physics, or chemistry et al.) should be included in the test of invariance across subjects.

\section{DATA AVAILABILITY STATEMENT}

The raw data supporting the conclusions of this manuscript will be made available by the authors, without undue reservation, to any qualified researcher.

\section{ETHICS STATEMENT}

The studies involving human participants were reviewed and approved by the Ethics Committee of School of Psychology, Capital Normal University. Written informed consent from the participants' legal guardian/next of kin was not required 
to participate in this study in accordance with the national legislation and the institutional requirements.

\section{AUTHOR CONTRIBUTIONS}

ZL conceived the research idea, made the research design, organized the research, interpreted the results, and drafted and revised the manuscript. YD conceived the research idea, made the research design, performed the studies, and analyzed the data. WX performed the studies, analyzed the data, and interpreted the results. All authors contributed to writing sections of the manuscript, and read and approved the submitted version.

\section{REFERENCES}

Alexander, P. A., and Jetton, K. T. L. (1994). The role of subject-matter knowledge and interest in the processing of linear and nonlinear texts. Rev. Educ. Res. 64, 201-252. doi: 10.2307/1170694

Cheung, G. W., and Rensvold, R. B. (2002). Evaluating goodness-of-fit indexes for testing measurement invariance. Struct. Equ. Modeling 9, 233-255. doi: 10.1207/s15328007sem0902-5

Cole, D. A., and Maxwell, S. E. (1985). Multitrait-multimethod comparisons across populations: a confirmatory factor analytic approach. Multivar. Behav. Res. 20, 389-417. doi: 10.1207/s15327906mbr2004-3

Csikszentmihalyi, M., and Hunter, J. (2003). Happiness in everyday life: the uses of experience sampling. J. Happiness Stud. 4, 185-199. doi: 10.1023/a: 1024409732742

Csikszentmihalyi, M., and Rathunde, K. (1992). The measurement of flow in everyday life: toward a theory of emergent motivation. Nebr. Sym. Motiv. 40, 57-97. doi: 10.1186/1471-230X-11-32

Deci, E. L. (2010). "Intrinsic motivation," in Corsini Encyclopedia of Psychology, eds I. B. Weiner, and W. E. Craighead, (New York, NY: John Wiley \& Sons). doi: 10.1002/9780470479216.corpsy0467

Denner, J., Valdes, O., Dickson, D. J., and Laursen, B. (2019). Math interest and selfconcept among latino/a students: reciprocal influences across the transition to middle school. J. Adolesc. 75, 22-36. doi: 10.1016/j.adolescence.2019.06.015

Dewey, J. (1913). Interest and Effort in Education. Cambridge, MA: Riverside Press.

Dotterer, A. M., Mchale, S. M., and Crouter, A. C. (2009). The development and correlates of academic interests from childhood through adolescence. J. Educ. Psychol. 101, 509-519. doi: 10.1037/a0013987

Elliot, A. J., and Church, M. A. (1997). A hierarchical model of approach and avoidance achievement motivation. J. Pers. Soc. Psychol. 72, 218-232. doi: 10. 1037//0022-3514.72.1.218

Frenzel, A. C., Goetz, T., Pekrun, R., and Watt, H. M. G. (2010). Development of mathematics interest in adolescence: influences of gender, family, and school context. J. Res. Adolesc. 20, 507-537. doi: 10.1111/j.1532-7795.2010. 00645.x

Gogol, K., Brunner, M., Martin, R., Preckel, F., and Goetz, T. (2015). “Towards an integrative model of students' affective-motivational experience," in Proceedings at Academic Self-Concept Formation: Broadening Our Perspectives Symposium Conducted at the Eighth Self Biennial International Conference, eds F. Preckel, and J. Möller, (Kiel).

Gogol, K., Brunner, M., Martin, R., Preckel, F., and Goetz, T. (2017). Affect and motivation within and between school subjects: development and validation of an integrative structural model of academic self-concept, interest, and anxiety. Contemp. Educ. Psychol. 49, 46-65. doi: 10.1016/j.cedpsych.2016. 11.003

Guo, Z. F., and Zhang, D. Q. (2012). The main reason of learning weariness in primary school students: the overburden of study load. Res. Basic Edu. 18, 3-5.

Harackiewicz, J. M., Durik, A. M., Barron, K. E., Linnenbrink-Garcia, L., and Tauer, J. M. (2008). The role of achievement goals in the development of interest: reciprocal relations between achievement goals, interest, and

\section{FUNDING}

This work was supported by the Beijing Social Science Fund in China (Project No. 16JYB008).

\section{ACKNOWLEDGMENTS}

We are grateful to all the adolescents, and teachers who participated in or contributed to this project. We want to acknowledge the contribution of Meifeng Qie, Jiacan Sun, Wenjing Yuan, Yaqing Shen, Xiaotong Han, and Chi Wang for assistance in collecting the data.

performance. J. Educ. Psychol. 100, 105-122. doi: 10.1037/0022-0663.100. 1.105

Hau, K., Marsh, H., and Wen, Z. (2004). Goodness of fit measures in structural equation modeling. Int. J. Psychol. 39, 513-513.

Hayton, J. C., Allen, D. G., and Scarpello, V. (2004). Factor retention decisions in exploratory factor analysis: a tutorial on parallel analysis. Organ. Res. Methods 7, 191-205. doi: 10.1177/1094428104263675

Hidi, S. (1990). Interest and its contribution as a mental resource for learning. Rev. Educ. Res. 60, 549-571. doi: 10.3102/00346543060004549

Hidi, S., and Baird, W. (1986). Interestingness-a neglected variable in discourse processing. Cognitive Sci. 10, 179-194. doi: 10.1207/s15516709cog 1002-3

Hidi, S., and Harackiewicz, J. M. (2000). Motivating the academically unmotivated: a critical issue for the 21st century. Rev. Educ. Res. 70, 151-179. doi: 10.3102/ 00346543070002151

Hidi, S., and Renninger, K. A. (2006). The four-phase model of interest development. Educ. Psychol. 41, 111-127. doi: 10.1207/s15326985ep 4102-4

Hidi, S., Renninger, K. A., and Krapp, A. (2004). "Interest, a motivational variable that combines affective and cognitive functioning," in Motivation, Emotion And Cognition: Integrative Perspectives On Intellectual Functioning And Development, eds D. Dai, and R. Sternberg, (Mahwah, NJ: Lawrence Erlbaum), 89-115.

Hoffmann, L. (2002). Promoting girls' interest and achievement in physics classes for beginners. Learn. Instr. 12, 447-465. doi: 10.1016/S0959-4752(01)00 010-X

Høgheim, S., and Reber, R. (2015). Supporting interest of middle school students in mathematics through context personalization and example choice. Contemp. Educ. Psychol. 42, 17-25. doi: 10.1016/j.cedpsych.2015.03.006

Horn, J. L. (1965). A rationale and test for the number of factors in factor analysis. Psychometrika 32, 179-185. doi: 10.1007/BF02289447

Horn, J. L., and Mcardle, J. J. (1992). A practical and theoretical guide to measurement invariance in aging research. Exp. Aging Res. 18, 117-144. doi: $10.1080 / 03610739208253916$

Hu, L., and Bentler, P. M. (1999). Cutoff criteria for fit indexes in covariance structure analysis: conventional criteria versus new alternatives. Struct. Equ. Modeling 6, 1-55. doi: 10.1080/10705519909540118

Izard, C. E. (1991). Emotions, Personality, and Psychotherapy. New York, NY: Plenum Press.

Jansen, M., Lüdtke, O., and Schroeders, U. (2016). Evidence for a positive relation between interest and achievement: examining between-person and withinperson variation in five domains. Contemp. Educ. Psychol. 46, 116-127. doi: 10.1016/j.cedpsych.2016.05.004

Jõgi, A. L., Kikas, E., Lerkkanen, M. K., and Mägi, K. (2015). Cross-lagged relations between math-related interest, performance goals and skills in groups of children with different general abilities. Learn. Individ. Differ. 39, 105-113. doi: 10.1016/j.lindif.2015.03.018

Kalender, I., and Berberoglu, G. (2009). An assessment of factors related to science achievement of turkish students. Int. J. Sci. Educ. 31, 1379-1394. doi: 10.1080/ 09500690801992888 
Kline, R. B. (2005). Principles and Practices Of Structural Equation Modeling, 2nd Edn. New York, NY: Guilford Press.

Koller, O., Baumert, J., and Schnabel, K. (2001). Does interest matter? the relationship between academic interest and achievement in mathematics. J. Res. Math. Educ. 32, 448-470. doi: 10.2307/749801

Krapp, A. (1999). Interest, motivation and learning: an educationalpsychological perspective. Eur. J. Psychol. Educ. 14, 23-40. doi: 10.2307/2342 0114

Krapp, A. (2000). "Interest and human development during adolescence: an educational-psychological approach," in Motivational Psychology of Human Development, ed. J. Heckhausen, (London: Elsevier), 109-208.

Krapp, A. (2002). Structural and dynamic aspects of interest development: theoretical considerations from an ontogenetic perspective. Learn. Instr. 12, 383-409. doi: 10.1016/S0959-4752(01)00011-1

Krapp, A. (2005). Basic needs and the development of interest and intrinsic motivational orientations. Learn. Instr. 15, 381-395. doi: 10.1016/j.learninstruc. 2005.07.007

Krapp, A., and Fink, B. (1992). "“'The development and function of interests during the critical transition from home to preschool," in The Role of Interest in Learning and Development, eds K. A. Renninger, S. Hidi, and A. Krapp, (Hillsdale, NJ: Lawrence Erlbaum Associates, Inc.), 397-429.

Krapp, A., Hidi, S., and Renninger, K. A. (1992). "Interest, learning, and development," in The Role of Interest in Learning and Development, eds S. Hidi, and A. Krapp, (Hillsdale, NJ: Erlbaum), 3-25.

Lazarides, R., Gaspard, H., and Dicke, A. (2019). Dynamics of classroom motivation: teacher enthusiasm and the development of math interest and teacher support. Learn. Instr. 60, 126-137. doi: 10.1016/j.learninstruc.2018. 01.012

Lei, L., Ma, X. H., and Wang, W. (2012). Development and application of the scale for adolescents'. Flow State in Learning. Psychol. Res. 5, 45-48.

Lin, J. B., and Chai, J. (2017). Formulation of sports learning interest scale and the norm of primary and secondary school students. J. Shenyang Sport U 5, 109-115.

Linnenbrink-Garcia, L., Durik, A. M., Conley, A. M., Barron, K. E., Tauer, J. M., Karabenick, S. A., et al. (2010). Measuring situational interest in academic domains. Educ. Psychol. Meas. 70, 647-671. doi: 10.1177/001316440935 5699

Lipstein, R., and Renninger, K. A. (2006). “"Putting things into words":12-15-yearold students' interest for writing," in Motivation and Writing: Research and School Practice, eds P. Boscolo, and S. Hidi, (New York, NY: Kluwer Academic).

Marsh, H. W. (1994). Confirmatory factor analysis models of factorial invariance: a multifaceted approach. Struct. Equ. Modeling 1, 5-34. doi: 10.1080/ 10705519409539960

Maurice, J. V., Dörfler, T., and Artelt, C. (2014). The relation between interests and grades: path analyses in primary school age. Int. J. Educ. Res. 64, 1-11. doi: 10.1016/j.ijer.2013.09.011

Mazer, J. P. (2013). Associations among teacher communication behaviors, student interest, and engagement: a validity test. Commun. Educ. 62, 86-96. doi: 10. 1080/03634523.2012.731513

Mcdonald, R. P., and Ho, M. H. R. (2002). Principles and practice in reporting structural equation analyses. Psychol. Methods 7, 64-82. doi: 10.1037/1082989X.7.1.64

Meredith, W. (1993). Measurement invariance, factor analysis and factorial invariance. Psychometrika 58, 525-543. doi: 10.1007/BF0229 4825

Mitchell, M. (1993). Situational interest: its multifaceted structure in the secondary school mathematics classroom. J. Educ. Psychol. 85, 424-436. doi: 10.1037/ 0022-0663.85.3.424

Muthén, L. K., and Muthén, B. O. (2012). Mplus User's Guide, 7th Edn. Los Angeles, CA: Muthén \& Muthén.

Nunnally, J. C., and Bernstein, I. (1994). Psychometric Theory, 3rd Edn. New York, NY: McGraw-Hill.

Nurmi, J. E., and Aunola, K. (2005). Task-motivation during the first school years: a person-oriented approach to longitudinal data. Learn. Instr. 15, 103-122. doi: 10.1016/j.learninstruc.2005.04.009

Nurmi, J. E., Leskinen, E., and Aunola, K. (2011). Developmental dynamics between mathematical performance, task motivation, and teachers' goals during the transition to primary school. Brit. J. Educ. Psychol. 76, 21-40. doi: 10.1348/ 000709905X51608

Prenzel, M. (1998). “"Interest research concerning the upper secondary level, college, and vocational education: an overview," in Interest and learning: Proceedings of the Seeon-Conference on interest and gender, eds L. Hoffmann, et al. (Kiel: IPN), 355-363.

Renninger, K. A. (2000). "Individual interest and development: implications for theory and practice," in Intrinsic and Extrinsic Motivation. the Search for Optimal Motivation and Performance, eds C. Sansone, and J. M. Harackiewicz, (New York, NY: Academic), 375-404.

Rotgans, J. I. (2015). Validation study of a general subject-matter interest measure: the individual interest questionnaire (iiq). Health Prof. Educ. 1, 67-75. doi: 10.1016/j.hpe.2015.11.009

Schafer, J. L., and Graham, J. W. (2002). Missing data: our view of the state of the art. Psychol. Methods 7, 147-177. doi: 10.1037//1082-989x.7. 2.147

Schiefele, U. (1991). Interest, learning, and motivation. Educ. Psychol. 26, 299-323. doi: $10.1207 / s 15326985 \mathrm{ep} 2603 \% 264 \_5$

Schiefele, U. (2009). "“Situational and individual interest," in Handbook of Motivation at School, eds K. R. Wentzel, and A. Wigfield, (London: Routledge), 197-222.

Schiefele, U., Krapp, A., and Winteler, A. (1988). "Conceptualization and measurement of interest," in Paper Presented at the Annual Meeting of the American Educational Research Association, New Orleans, LA.

Schmitt, N. (1982). The use of analysis of covariance structures to assess beta and gamma change. Multivar. Behav. Res. 17:343. doi: 10.1207/s15327906mbr $1703 \_3$

Schurtz, I. M., Pfost, M., Nagengast, B., and Artelt, C. (2014). Impact of social and dimensional comparisons on student's mathematical and English subjectinterest at the beginning of secondary school. Learn. Instr. 34, 32-41. doi: 10.1016/j.learninstruc.2014.08.001

Shernoff, D. J., Csikszentmihalyi, M., Shneider, B., and Shernoff, E. S. (2014). Student engagement in high school classrooms from the perspective of flow theory. School Psychol. Quart. 18, 158-176. doi: 10.1521/scpq.18.2.158. 21860

Tang, L. I., and Toyama, M. (2016). Change trajectories of college students' interest in their major: development of a domain learning interest scale for college students. Jpn. J. Educ. Psychol. 64, 212-227. doi: 10.5926/jjep. 64.212

Tobias, S. (1994). Interest, prior knowledge, and learning. Rev. Educ. Res. 64, 37-54. doi: $10.2307 / 1170745$

Todt, E., Schreiber, S., and Baumert, J. (1998). "Development of interests," in Interest and learning: Proceedings of the Seeon-Conference on interest and gender, eds L. Hoffmann, A. Krapp, and K. Ann Renninger, (Kiel: IPN), 25-40.

Trautwein, U., L'udtke, O., Nagy, N., Lenski, A., Niggli, A., and Schnyder, I. (2015). Using individual interest and conscientiousness to predict academic effort: additive, synergistic, or compensatory effects? J. Pers. Soc. Psychol. 109, 142-162. doi: $10.1037 /$ pspp0000034

Tu, Y. j, and He, X. M. (2013). Comments on students' learning interest measurement research. Univ. Edu. Sci. 1, 52-58.

Vandenberg, R. J., and Lance, C. E. (2000). A review and synthesis of the measurement invariance literature: suggestions, practices, and recommendations for organizational research. Organ. Res. Methods 3, 4-70. doi: $10.1177 / 109442810031002$

Viljaranta, J., Tolvanen, A., Aunola, K., and Nurmi, J. E. (2014). The developmental dynamics between interest, self-concept of ability, and academic performance. Scand. J. Educ. Res. 58, 734-756. doi: 10.1080/00313831.2014. 904419

Wang, Y. M., Liu, X. M., Guo, D. J., and Song, J. F. (2006). Intrinsic motivations of different goal-oriented students in two conditions. Psychol. Sci. 29, 103-106.

Wang, Z., and Adesope, O. (2016). Exploring the effects of seductive details with the 4-phase model of interest. Learn. Motiv. 55, 65-77. doi: 10.1016/j.lmot.2016. 06.003

Wininger, S. R., Adkins, O., Inman, T. F., and Roberts, J. (2014). Development of a student interest in mathematics scale for gifted and talented programming identification. J. Adv. Acad. 25, 403-421. doi: 10.1177/1932202X145 4935 
Wu, H. Y., and Liu, X. L. (2017). Development of mathematics learning interest questionnaire and the investigation on junior high school students. J. Math. Educ. 26, 50-54.

Zhang, J., Dong, Z. H., and Yang, X. D. (2018). The predictors of academic interest: fluid intelligence, openness, and their interaction. Educ. Psychol. 39, 1-19. doi: $10.1080 / 01443410.2018 .1514103$

Zhao, X. T. (2015). The transformation and management of rural middle school students who suffered from learning weariness from the perspective of self-awareness. J. Jinzhong $U$ 32, 88-91.
Conflict of Interest: The authors declare that the research was conducted in the absence of any commercial or financial relationships that could be construed as a potential conflict of interest.

Copyright (c) 2019 Luo, Dang and Xu. This is an open-access article distributed under the terms of the Creative Commons Attribution License (CC BY). The use, distribution or reproduction in other forums is permitted, provided the original author(s) and the copyright owner(s) are credited and that the original publication in this journal is cited, in accordance with accepted academic practice. No use, distribution or reproduction is permitted which does not comply with these terms. 


\section{APPENDIX}

The 29-item Academic Interest Scale for Adolescents (AISA) in English and Chinese.

\section{Emotion}

3

5

8

13

14

18

26

Value

1

10

16

17

20

24

27

29

\section{Knowledge}

4

7

9

12

15

22

23

Engagement

2

6

11

19

21

25

28
I understand the fun of ... 我能体会...的乐趣

Studying .... makes me feel happy 学习...让我感到开心

I am interested in ... 我对...感兴趣

The content I learn from ... courses is interesting ...课所学内容很有意思

I enjoy studying ....... 我找到了学习...的快乐

I really like ... courses 我很喜欢...课

I enjoy when I study ... 学习...时, 我乐在其中

The knowledge of ... is important ... 知识很重要

A good mark in ... courses means a lot to me 在...学科取得好成绩对我来说很重要

I think that ... is helpful for my career in the future 我觉得...对我未来职业有帮助

The knowledge of .... makes my daily life easier ...知识对我的日常生活有帮助

The knowledge of ... promotes my growth ...知识对我的成长有帮助

I find that the knowledge of ... is useful in daily life 我发觉...知识对我日常生活很有用

The knowledge of ... is valuable for my future development ... 知识对我未来发展有价值

I think that learning ... is significant for my growth 我认为学习...对我成长有意义

I know all kinds of things about ...... 我知道...领域的各种知识

I am expert in ... 我擅长...

I can answer all kinds of questions that teachers ask in the ... class 我能回答出老师在...课上提的各种问题

I am familiar with the knowledge and skills required in ... 我熟悉很多...的知识和技能

I do well in ... lessons 我在...课上表现得好

I have a lot of things to say about ... topics 有关...领域的话题, 我有很多东西可以讲

I have a lot of knowledge about... 我拥有大量...知识

I want to learn things that are not included in ... textbooks 我想学...课本里没有的东西

I hope to explore things about ...... 我希望探索...方面的东西

I will read more books about ... if I have the chance 如果有机会, 我会读更多有关...的书

I want to know more things about the field of ... 我想深入了解...领域的东西

I will take part in an extracurricular training class for ... if I have the opportunity 如果有机会, 我会参加...课外培训班

I want to find various ways to complete the ... assignment 我想找到多种方法来完成...作业

I am willing to spend time on the skills or methods learned from ... lessons 我愿意花时间练习...课上学到的技能或方法 